\title{
4. Governments Fit for the Future: Lessons in building resilience
}

\author{
The Honourable Jocelyne Bourgon
}

In this chapter I will explore the topic of building more resilient communities and public institutions, drawn from the lessons of the 'New Synthesis Project' (Bourgon 2011). The theme of resilience is very much related to the theme of the social context or landscape within which governments are called upon to serve, the increasing complexity of the issues they have to deal with, and the increasing volatility of the environment within which they have to make policy decisions and take action.

For some, the concept of resilience brings to mind images of catastrophic failures, natural disasters and pandemic diseases, because resilience is on such strong display in those circumstances. But I prefer to explore the concept of resilience in a softer way. Yes, it is strongly on display when you say a society is able to weather a crisis and emerge from it stronger than before. I would argue, however, that resilience is also on display when countries and public institutions show they are able to adapt, evolve and transform themselves in response to changing circumstances - and are able to do it in a manner that avoids crises and reduces the risk of failure, in particular when the costs of these failures will be borne by society as a whole.

The first point to make about resilience is that it is built gradually over a long period. This is what is needed if it is going to be in abundant supply when countries need it most. Resilience is found in self-reliant individuals who are able to take charge of their lives and find solutions to the problems they are facing; it is found in the bonds and the relationships of trust between individuals, families, communities and public institutions. And it is found in public institutions which are able to adapt to changing circumstances and coevolve with society.

I believe that focusing on resilience can help us shed a different light on the role of government in society, and the relationship between government, citizens and society. In the course of this chapter, I will draw freely from a project conducted over a couple of years that has explored a new synthesis of public administration. Called the New Synthesis Project, it involved senior practitioners and academics from six countries working as partners. By bringing together a representative sample of national public administrations, we were able to benefit from the richness of diversity of socioeconomic circumstances, history, ideology, culture, language and so on. 
Countries were selected to give a truly global spread: there are two from the Americas (Canada and Brazil); two from Europe (The Netherlands and the United Kingdom); and two from the Asia-Pacific region (Singapore and Australia). But there is also a huge degree of diversity in this matrix, reflected in the vastly different geographies, demographics, democratic histories and economic situations that these six countries have. And this diversity was the starting point of our research project about governance in the twenty-first century: are those differences significant enough to change our practices, and if so, what do these different approaches entail?

\section{Building on Strong Foundations for Resilient Capacities}

We live in a world which is increasingly complex, volatile and prone to global cascading failure. As a consequence, governments today are called upon not simply to do what is predictable (to do it with increasing productivity, performance and efficiency), but they are also expected to effectively address those issues that are beyond what can be predicted, and to do this in a way that improves the capacity of society to absorb shock and disturbances, and to prosper in all circumstances.

I would argue that the task of those who are in government today is more challenging than ever before. There is now a long list of potential crises a government can face-some predictable and preventable, others not. Governments today must accept and recognise that there is every reason to believe that the frequency and the scale of shock from crises and disturbances will continue to increase.

When it comes to building resilience, there is no doubt there are many people across the globe who have invested years of effort in conducting relevant public service reform and exploring why we are not better prepared and equipped to anticipate and prevent crises. These people strive to steer their respective countries in a way so that they can prosper and adapt to changing circumstances. They have adopted business principles to improve productivity; centred many policies on citizens, with greater focus on user satisfaction; and they have eliminated sizeable government deficits (although post GFC many other nations have to relearn how to balance their books).

No-one is disputing the commitment of the men and women around the world who have been leading ambitious public sector reforms aimed at increasing the resilience of their states; but we need to delve into this issue more deeply. The reformers have given us solid foundations but these are insufficient to address 
some of the complex problems we are now facing. Their reforms did not prepare government for the problems that stem from living in a post-industrial world. So, in spite of all these reformist efforts, in spite of all this energy and courage, we need to ask ourselves: is there a systemic reason that explains why it is still so difficult to depart from the traditional ways of governing our societies?

To address this question, it is valuable to consider where the governance system in our respective countries comes from. In most cases, the system of public administration in place has evolved over hundreds of years, taking its modern shape from the late nineteenth century and early twentieth century. This period was characterised by a process of change related to industrialisation and democratisation. Looking at the systems of public administration that are deeply entrenched across the OECD, you find fundamental institutions and conventions that have served their countries well and have given them strong foundations. But these systems also beg the question: what is the ongoing contribution of these institutions and conventions to governing in the future? From the 'industrial age' we inherited a system of public administration premised on a political system governed by the rule of law. Together these systems value due process and a delegated authority that are the bases for control, accountability and performance management; they became systems ideally suited to the mass production of public services.

At the same time, a particular strength in some circumstances can become a weakness in others. While traditional systems of public administration may be ideally suited to the mass production of public services, they have found difficulty in anticipating what is needed for a society to adapt to that which is not foreseen and not predicted. Hence, our starting point in the New Synthesis Project was to recognise that traditional approaches of public administration leave governments in a reactive position when it comes to unpredictable shocks and crises. Therefore, we needed to improve our capacities to anticipate, to introduce proactive interventions and course corrections, and to build capacities to absorb shocks and disturbances.

There is more to the role of our public services than the programs they administer and the services they provide. They serve a broader public purpose, and whatever they do has wider ramifications beyond the authority and responsibility they operate within - in particular, they contribute to systemwide results reflected in societal results. To achieve these public results, we build self-reliant individuals and resilient communities; we develop a sense of civic spirit that is conducive to collective actions and a sense of working together to achieve better results at a lower overall cost. A country with these attributes is better positioned not only in predictable and favourable circumstances, but also in unpredictable and chaotic circumstances. 
Yet many problems in society exceed the capacity of government when working alone. Their traditional powers, such as the authority to legislate and to enforce laws or powers to tax and spend, are not sufficient to be effective on their own. Governments need to work with and through others to achieve public results. All the instruments of state have to be used to lever greater collective capacity in society to achieve better results and allow the entire society to make contributions to the value-adding chain. This opens up an expanding space of possibilities as governments contemplate the complex decisions necessary to achieve improved societal results.

\section{Improving Institutional Capacities}

In order to focus on these broader possibilities, we need to improve our institutional capacities - the very institutions that govern society that evolved over a long period. We need to strengthen the organisational capacity of our public sector organisations so they are not only efficient but also contributing to future societal benefits. We want them to have the capacity to work collaboratively with each other (multi-institutional) and to engage across the community and private sectors.

We also need a society and government able to innovate, shape so-called 'emergent solutions', and to find and address the complex problems we are facing. Moreover, no matter how smart governments are, they need to develop a very strong adaptive capacity because there will be unpredictable shocks and crises. If they are successful in escaping the traditional triangular definition of public administration (based on the rule of law, the separation of politics from administration, and a merit-based career public service characterised by political neutrality and anonymity), they will have something that is much closer to a dynamic and adaptive system, where government transforms society and must be transformed by society, and where the government adapts to changing circumstances on an ongoing basis.

Institutions, then, are not necessarily fit for the challenges they confront or face ahead. I will cite two examples briefly. The European Union is in trouble because the institutions that have been created are not commensurate to the problems they are facing. There is an increasing gap between the aspirations, the challenges at hand and the capacity of the collective institutions that have been created. The United States is also facing a crisis of authority, because the institutions they have created to introduce checks and balances to serve the collective interests have lost sight of this purpose. The strength of 'blocking' interest groups is now greater than the collective instrument that should give effect to the will of the majority. 
In short, no institutional arrangement is appropriate for all time: it needs to be able to adapt to changing circumstances. That is part of the challenge for people in government - not only to deal with the immediate policy issue or firefighting crisis of the day, but also to make sure that as the guardian of public institutions, we bring in the capacity to adapt on an ongoing basis. I would venture a hypothesis: the developed countries that have been the most successful with the previous concept of governance may find it more difficult to adapt than those which are inventing and creating a different model of governance.

\section{Framing an Adaptive System of Governance}

The conclusion to this point is that different times require different ways of thinking, different mental maps and forms of openness to different ways of doing things. I believe we need a new analytical framework to create a government fit for the future, and we need to work out the interconnections between the four essential functions of governance: compliance, performance, emergence and resilience (as shown in Figures 4.1 and 4.2, spanning the continuum between predictability and unpredictability). We need a compliance function that we know well; we also need a performance function to deliver outputs, an emergence function to anticipate likely scenarios and a resilience function to build enduring capacity. These four functions must work together to produce an adaptive government (Figure 4.2), and in the rest of this chapter I will explore some of the innovative practices that are emerging as powerful connectors of these four functions: anticipatory abilities and adaptability through cocreation and co-production. These connectors increase the adaptive capacity of government, and contribute to the government's resilience.

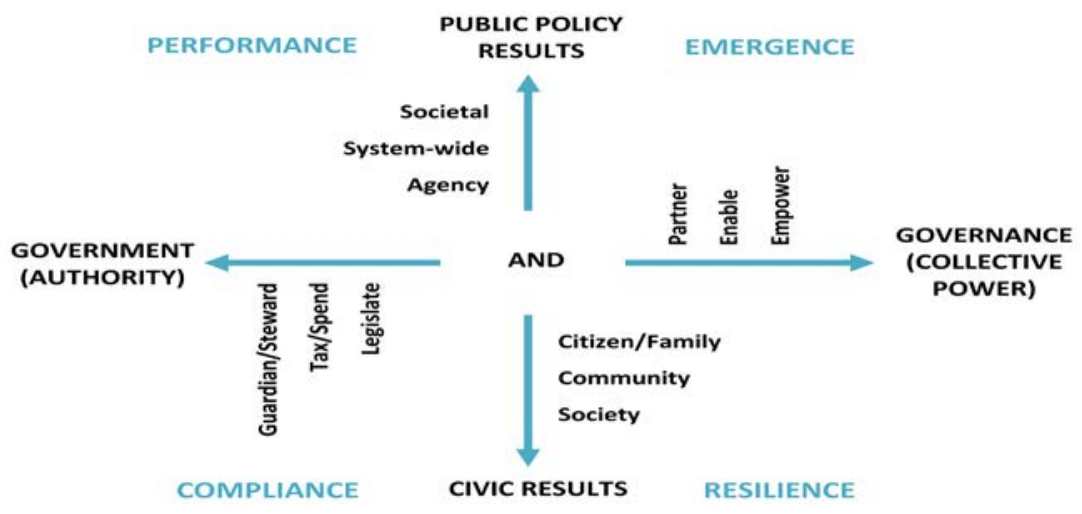

\section{Figure 4.1 Functions of government}




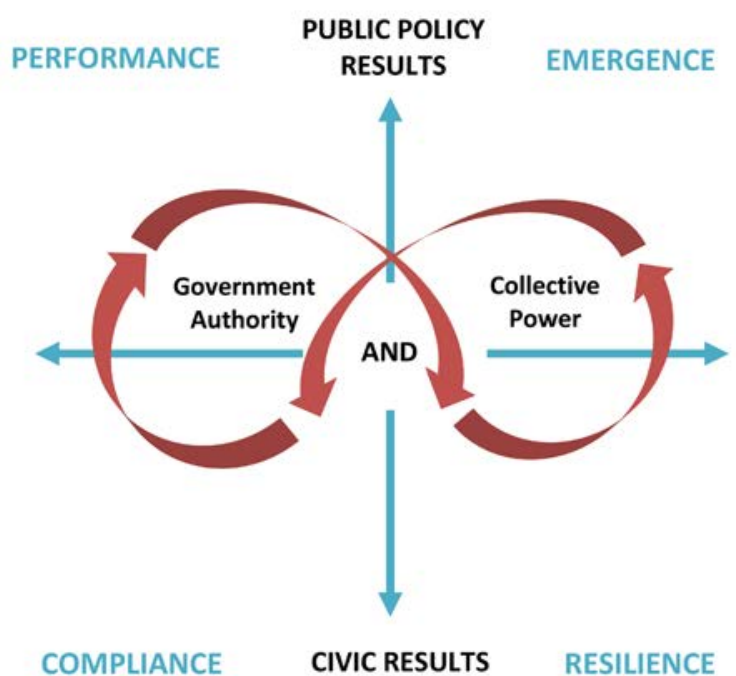

Figure 4.2 An Adaptive System of Government

Source: ANZSOG, after Bourgon 2011.

We need an emergence function to be able to anticipate and to introduce course correction and to do it before time. In particular, when the cost of failure will be borne by society as a whole, we need to be able to shape solutions in a more organic way than we have been able to do in the past. We need constantly to be aware of this insight and conserve energy; we need the stability and predictability provided by institutions so we can cope with the volatility that is out there. We need to be able to work across and we need to be able to adapt. So what are the important connectors that link these four essential functions?

First, anticipation is a key quality if we want to prevent crises, and crisis prevention is far less costly than crisis recovery. I do not think our recent track record on crisis prevention has been as good as it could be. Singapore has a long tradition of looking far into the future and of long-term strategic planning. They developed the Risk Assessment and Horizon Scanning (RAHS) program and set up the Centre for Strategic Futures, both in 2009. These anticipatory ventures, perhaps the most sophisticated of their type in the world, enable Singapore to combine the strength of scanning and scenario planning with a strong focus on experimentation and innovation. Singapore's ability to detect emergent signals gives them an advantage to initiate proactive intervention. 
Other countries are undertaking similar futures exercises and foresight scenario planning initiatives. Finland has adopted a more political process involving an all-party parliamentary committee looking ahead 25 to 50 years. It is a public process and they engage civil society in a conversation about the future of their country. These initiatives give a country the advantage of better anticipation; however, countries which are investing in these practices over a long period derive more benefit than just the capacity to anticipate. They develop a high level of public understanding of the challenges faced in the country, the consequences of various choices and the trade-offs. That awareness facilitates consensus building, it improves the capacity to align leaders from the public, private and civil sectors, and improves the likelihood of success for an ambitious collective agenda.

By improving the capacity to focus on the future, we produce a long chain of interrelated results that improves the government's adaptive capacity more generally. In particular, we improve the government's capacity to blend shortterm considerations with long-term actions, and also society's capacity to develop an awareness of what might be a preferable future. So we have created a process of dynamic change, transforming government and society. This process builds resilience including the capacity to adapt to changing circumstances.

Second, co-creation is another important form of connection linking the four functions. Co-creation is the coming together of end users, beneficiaries, interested parties and service providers for the purpose of shaping, testing and experimenting with policy response in practice. It would be a mistake to prescribe co-creation in all circumstances as there will always be situations where governments are best positioned to act on their own. Governments are best positioned to act on their own when they can define the issue, when they have the necessary tools and can enact reform with confidence.

Let me provide an example of co-creation from Denmark. Denmark has a range of laws and programs supporting people with disabilities, but the Government faced a traditional dilemma: unlimited or growing demand, and limited or declining resources. In the traditional space policymakers have few options: they can explore how to do more with less; they can provide fewer services or make a case to inject more resources. The range of possible solutions in the traditional space is narrower than it needs to be; however, if governments explore the possibilities of co-creation then many more options are possible. In the Danish case, the first step was to map out each process or stage step undertaken by potential users - those trying to qualify for the services. The mapping report found major problems and paradoxically argued that a citizen would have to be healthy to go through all the hoops that are required in order to qualify for a program that is aimed at supporting disabled people. It also found public servants themselves had to go through many loops to provide the services for people with disabilities. 
Having done the client-mapping exercise and provided that to the stakeholder group, it was not hard to come up with better ways of doing things - a case of co-creation in practice. They tested various ideas and improvements and established they were working before they rolled them out nationally. They have evaluated the results from the first year, demonstrating that they have achieved better results with lower costs - an impressive achievement for a government operating under fiscal constraints. What is more impressive is that they have dramatically improved the satisfaction levels of their users. The Danes were prepared to test their ideas even if they could not establish direct causality between their proposals and the outcomes. They were prepared to experiment and explore co-creation because they believed they could come up with a better policy response.

Hence, public agencies have to be able to operate as experimentation platforms, which many of our agencies and departments have not been designed to do. They have neither the policies nor the infrastructure to facilitate that end. They are imbued in traditional ways of doing policy: undertaking research, devising policy options based on the best available knowledge, mapping out which options to take, and finally taking the option to a minister for a decision. These agencies generally do not have a safe space where policy workers can go and test ideas in practice or transform delivery processes, such as the Danish 'MindLab' initiative provides.

Good policy formulation depends on monitoring the implementation stages to examine whether the policy is achieving the intended result and/or becoming aware of unintended consequences. Hence, it is a more experimental and long-term process. We need to capture the implementation knowledge from stakeholders so we continue to improve the policy response-this gives policymakers a stronger adaptive capacity but also builds resilience. It builds resilience because it involves all stakeholders in a manner whereby they share responsibility for the result. And it develops a much more active relationship between government, users and beneficiaries.

Another possible connector is co-production. Co-creation of a solution by a group of diverse actors does not necessarily mean that government is obliged afterwards to co-produce the service with them. Co-creation and co-production could occur a long time apart and could involve different groups. In Bourgon (2011), there are many examples of co-production. Some are major undertakings and others are relatively minor. In Singapore a prison manager used coproduction to improve the successful reintegration of inmates. The manager reconceptualised the role of the prison, going from a focus on the agency's narrow results (the safekeeping of the inmates), to asking where does the prison add value in system-wide or societal terms? Once the prison authorities began to consider how systemic and societal factors and a range of outside actors 
affected results, they were better able to cooperate with these actors. In this case, mapping out individual prisoner's circumstances prompted prison authorities and stakeholders to conclude that they had to change public opinion about the benefits of facilitating more effective reintegration of inmates into the community. This new approach made it possible for employers to feel comfortable in offering jobs to former inmates, which in turn increased the confidence of inmates, who believed they had gained a second chance and a way to gain skills and support themselves once released. It also made the families of inmates more confident in supporting the inmate while they were still incarcerated. Ultimately, this process created a long chain of shared responsibilities. It produced a collective effort to achieve the intended results, which no single actor could do on their own (not the prison system, the families, employers or the community). This example is now supported by evidence from 10 years of data. Much progress has been achieved over the 10 years in the successful reintegration of ex-offenders, and the reduction of recidivism.

The second example concerns the transfer of welfare payments to the 50 million poorest families in Brazil, many living in remote communities. Traditional programs alleviating poverty were run out of individual departments, which addressed various aspects of the problem such as education, family and health problems. All of these departments ran good programs, but were effectively siloed in their approaches. Each program addressed one aspect or one consequence of poverty: poor children not going to school because they are put in the labour force, high child mortality because of poor health, and lack of attention to women during pregnancy, among others. Each program had a long list of factors that contributed to their success. They were well managed, complied with all the requirements of central agencies in a traditional way, and reported back to Parliament. The only problem was that poverty was not decreasing. It is the irony of public administration that officials can sometimes comply with every legal and political requirement and miss the mark of a program's intended purpose, which in this case was to reduce poverty. In Brazil's case, program redesign involved integrating all the services, removing virtually all the conditionality of the programs, and empowering the head of the family to receive the money and use it in the manner felt to be most appropriate - a huge act of faith. The head of the family would become an active co-producer in the achievement of results.

Media coverage of the policy change was ferociously hostile: it portrayed considerable sums of money being given to people who ostensibly could not be trusted; it suggested the money would be used for alcohol, drugs and other antisocial purposes. It took the strength of President Lula da Silva to proclaim that the Government refused to design a program based on distrust, and his administration would fix any problems whenever they found them along the way. Three program evaluations have now been completed: one by the United Nations, one internal program review and another by the World Bank/ 
International Monetary Fund (IMF). The program is now a source of inspiration to others in Latin America, even though it was challenged politically when it started. Furthermore, during the last election, every major Brazilian party publicly supported this as the best program they had to reduce poverty.

A third example involves the city of Charlotte in the US State of North Carolina, which reveals the potential for technology to enable self-organisation and to contribute to the adaptive capacity of society and build its resilience. Charlotte has a large, and therefore expensive, energy consumption footprint. The traditional approaches to manage energy usage by governments and their bureaucratic administrations involve taxation powers and pricing, legislation and regulation. Instead of adopting such traditional approaches, the Charlotte City Council forged an agreement with the owners of commercial buildings in the central part of the city to install large television screens in the foyers of these buildings that displayed to residents or workers up-to-the-minute information about the amount of energy being consumed by each building. Generally, these screens showed the energy consumption from the previous day and the previous week, and projected the present day's energy consumption as a way of showing users of the building how their behaviour was changing energy usage. Based on the initial phases of this initiative, the managers of the project expect a 20 per cent reduction of energy consumption within the first year.

A similar, smaller example of the benefits of co-production using technology occurred in downtown London over attempts to reduce the number of accidents involving cyclists in the area. Instead of adopting a traditional policy route to identify the problem - that is, creating a committee, commissioning a study, submitting to a parliamentary committee, taking the recommendations and then shaping policy based on the final report - what the City of London council did was simply to issue regular public data about the location of cycling accidents downtown. The local cycling association did the rest. They created an app that provided up-to-the-minute advice to cyclists about dangerous routes, congestion, what to avoid and how to navigate. The results were remarkable and the number of cycling accidents has been reduced. In both of these examples, no law was created or changed, no subsidy was given, no new tax was imposed; yet noticeable results were achieved. Public administration was used intelligently to encourage people to pursue their individual interest in a manner that also enhanced the collective interest.

What has emerged from these examples is that co-production starts from the fundamental notion not only that a user or a beneficiary of a government service should be considered a 'cost' to government in the short-term, but also that in the longer term, with proper investment in co-produced programs, users can become real assets. Moreover, if these assets are put to productive use in society, the results of social programs demonstrably improve and end up costing 
society less overall. A third finding from these processes has been the realisation that no country is rich enough not to put to productive use all available assets. Our experience with co-production processes has transformed our concept of service delivery: the responsibility for creating and achieving public results is not just a matter for government; it is a shared responsibility and requires a collective effort.

Significantly, new technologies have the potential to achieve an array of results in self-organisation and self-reliance. We have perhaps only just begun to explore the full potential of technology-enabled self-organisation. Governments could use these technologies to assist them to become 'fit for the future'. Technology is potentially more powerful and more cost-effective than creating a new funded program. It can be more efficient and more instrumental in changing behaviour than legislating, without the burden of compliance and enforcement that legislated approaches entail.

\section{Conclusion}

So, to conclude, resilience is ultimately a test of our capacity to adapt, to evolve and to prosper in a turbulent world. As I said at the beginning, resilience is not found in one place or in one format; indeed, paradoxically, the more despair and crises occur the better because resilience only develops through experience and learning. It is found in self-reliant individuals able to take charge of their future and solve problems. It is found in an innovative society able to shape emergent solutions to the complex problems of our time. It is found in relationships of trust and the social capital we accumulate over a long period. And it is in public institutions which are able to adapt to changing circumstances, because they are not fit for all time.

So, to paraphrase a famous quote, we cannot solve the problems we ourselves have created using the same thinking that was used when we created them. In this contribution, I tried to address the issue of what are the capacities of government administrations worldwide to give themselves different mental maps of our collective capacity, which in turn encourages more collective responsibility and inventive solutions to the constantly changing challenges of our complex post-industrial world.

\section{Reference}

Bourgon, J. 2011. A New Synthesis of Public Administration: Serving in the 21st Century (Montreal: McGill-Queen's University Press). 
This text taken from Future-Proofing the State: Managing Risks, Responding to Crises and Building Resilience, edited by Jonathan Boston, John Wanna, Vic Lipski and Justin Pritchard, published May 2014 by ANU Press, The Australian National University, Canberra, Australia. 